\title{
Experimental Research of the Usability on Double Acting Intensifiers in Hydroforming
}

\author{
Ahmet Can Günaydın ${ }^{1,3}$, Mehmet Halkacı ${ }^{2}$, Fatih Ateş ${ }^{3}$ and Hüseyin Selçuk Halkacı ${ }^{1}$ \\ ${ }^{1}$ Department of Mechanical Engineering, Selcuk University, Konya, Turkey \\ ${ }^{2}$ Technical Sciences Vocational School of Higher Education, Selcuk University, Konya, Turkey \\ ${ }^{3}$ Ermetal Otomotiv ve Eşya Sanayi Ticaret A.Ş., Bursa, TURKEY
}

\begin{abstract}
The hydroforming method is especially used for forming lightweight materials like aluminum, magnesium alloys, high strength steels or materials that have limited formability. Intensifiers are the most important component of hydroforming presses. Nowadays single-acting intensifiers are used in hydroforming presses. Single-acting intensifiers provide pressurized liquid by forwarding movement of the piston through one direction and their volumes are limited. The mass of the intensifiers increases significantly depending on their liquid volume capacity and this causes high manufacturing costs. For this reason, two or more single-acting intensifiers which bridged in a parallel circuit are used to manufacture bigger products that require a high volume of liquid. But this method is not an economical solution. So double-acting intensifiers can overcome this problem. The pressurized liquid can be obtained during both forward and backward movement of the piston in double-acting intensifiers which work like a pump. This is why double-acting intensifiers have no volume limit on the contrary of single-acting intensifiers. Yet there are sudden pressure drops in double-acting intensifiers caused by returning movements of the piston to pressurize liquid again. This pressure drops cause some problems to use double-acting intensifiers on hydroforming method. The situation of solving this problem to use double-acting intensifiers on the hydroforming method can eliminate limited volume problem and decrease investment cost of hydroforming presses. In this study, the usability of double-acting intensifiers on hydroforming with die method was investigated. Because of the existing hydroforming press, used in experiments, doesn't contain any double-acting intensifiers, pressure drops obtained by single-acting intensifier to perform simulated experiment. A die was designed and manufactured to synchronize the blank holder force with pressure drops. This die was integrated on the hydroforming press, located on Selcuk University Hydroforming Laboratory, for the success of the process. Performance of improved system was measured as well as repeatability of applying process parameters and product's geometry were determined. The AA5754 aluminum alloy used processes, both single- and double-acting intensifier, were compared. Limiting drawing ratios were determined for all processes. It is obtained that pressure drops have no negative influence on formability. Moreover, there is no difference observed in thickness distribution which is an indicator of product's quality and strength. However, when geometric accuracy was investigated then noticed that the pressure drops count has a good influence on product radius. $5.96 \mathrm{~mm}$ product radiuses on the process with single-acting intensifier was obtained 5.92 and $5.10 \mathrm{~mm}$ by using double-acting intensifier increasing pressure drop's frequency.
\end{abstract}

\section{Introduction}

The hydroforming method widely used, in developed countries today, as an alternative to conventional sheet stretching and deep drawing processes. The process is also used in mass production of automotive, white goods and plate heat exchanger due to the low cost and other advantages. Although the forming process in conventional methods is performed between a female and male die, only one of these dies is used in hydroforming method. High fluid pressure takes the other die's place and thus provides a possibility of flexible forming. By this method, in addition to manufacture of more complex parts, the quality of the final product is better compared to conventional method.
In the hydroforming process, very high pressure is required during the production. For this reason, the pressure intensifier (PI) which provides the necessary high pressure is the most important element of hydroforming presses. The fluid volume required for forming varies directly proportional with the volume of the workpiece. The volume of fluid required for forming is one of the important criteria for hydroforming presses and acts directly on the manufacturability of the part. Depending on the fluid volume capacity the mass of intensifier increases significantly. This leads to the increased cost of production of the single acting pressure intensifiers (SAPI) used in the hydroforming process (Figure 1). 


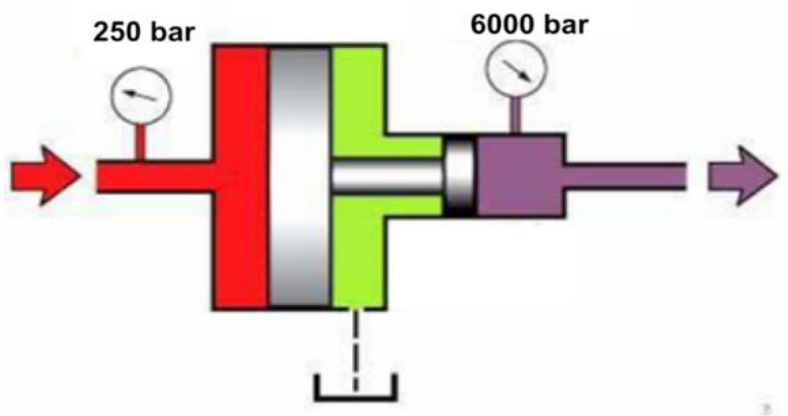

Figure 1. Single acting pressure intensifier

Nowadays SAPIs are used in the hydroforming presses. The volume of the SAPI is constant and ensures the pressure with the move of the piston in one direction. This means that when the piston reaches the end of its stroke it cannot provide pressure anymore. Therefore, producing workpieces requiring a greater volume than the volume provided by the SAPI is not possible (Figure 2). For the workpieces that require large volumes, the fixed-volume SAPI are connected parallel to get the required volumes. But taking into account the costs depending on the size, weight and quantity of the SAPI this method does not seem as an economic solution.

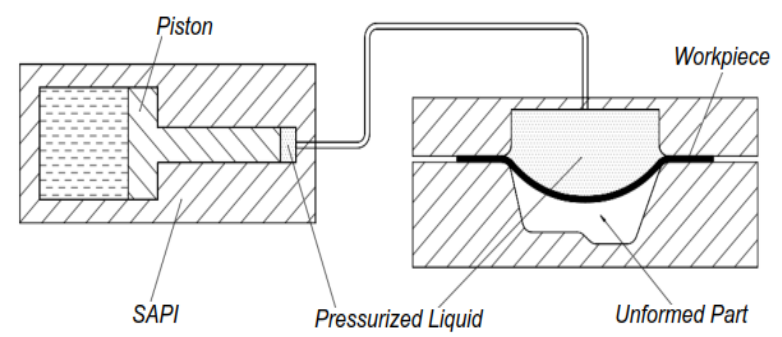

Figure 2. Semi-formed part of workpiece when using SAPI in hydroforming

It may be able to overcome this problem with doubleacting pressure intensifiers (DAPI). In the double-acting (continuous flow) pressure intensifiers, of which the operating principle is given in Figure 3, pressure can be achieved by both forward and backward movement of the piston. Therefore, unlike the fixed-volume SAPIs, there is no limit for the fluid volume to be provided by DAPIs.

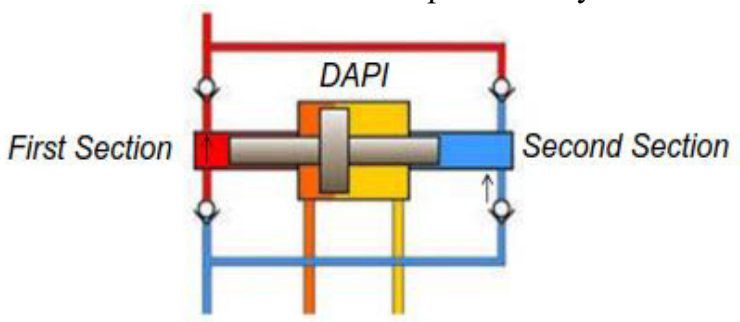

Figure 3. Double-acting pressure intensifiers

In the DAPIs sudden pressure drops occur during the back movement of the piston, as shown in Figure 4. These decreases directly affect the blank holder force which is one of the most important parameters of the hydroforming method. Therefore, it will be quite difficult to control the blank holder force which is changing with the pressure. Also those pressure drops and it's characteristic (count, slope etc.) will affect the workpiece's quality and limiting drawing ratio (LDR).

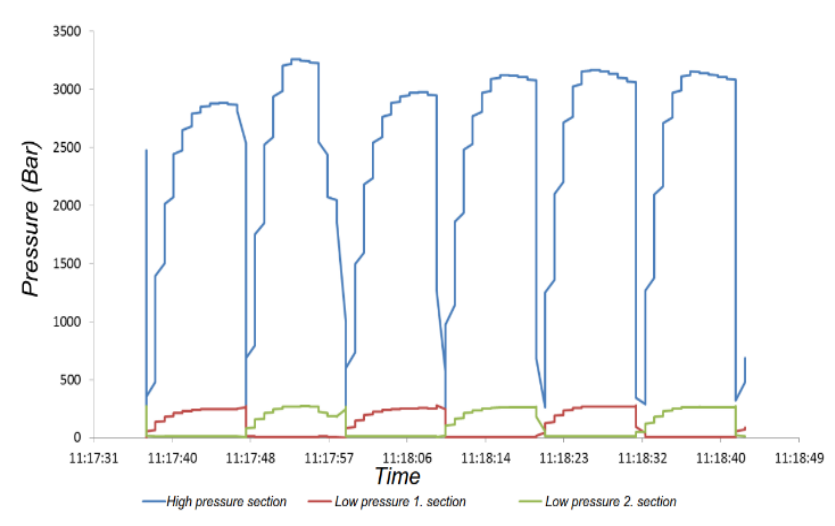

Figure 4. Pressure drops in DAPI

\section{Material and methods}

In this study, AA5754 (Al-Mg Alloy, thickness: $0.6 \mathrm{~mm}$ ) was used due to frequency of occurrence in construction, marine and especially automotive industry for its strength, excellent corrosion resistance, high-toughness and good weldability (Table 1).

Table 1 AA5754's chemical components

\begin{tabular}{lllllllll}
\hline$\%$ & $\%$ & $\%$ & $\%$ & $\%$ & $\%$ & $\%$ & $\%$ & $\%$ \\
$\mathrm{Cu}$ & $\mathrm{Mg}$ & $\mathrm{Mn}$ & $\mathrm{Fe}$ & $\mathrm{Si}$ & $\mathrm{Zn}$ & $\mathrm{Ti}$ & $\mathrm{Cr}$ & $\mathrm{Al}$ \\
\hline 0. & 2. & 0. & 0. & 0. & 0. & 0. & 0. & 96. \\
037 & 79 & 28 & 269 & 17 & 063 & 012 & 036 & 29 \\
\hline
\end{tabular}

Dies were designed for Sheet Hydroforming with Die (SHF-D) process compatible with hydroforming press in Selcuk University. Design fundamental like sealing, dies connection to the hydroforming press, evacuation of pressurized liquid, etc. is considered in design stage.

Using DAPI in SHF-D requires high accuracy on control of Blank Holder Force (BHF) that must be synchronize with pressure. BHF is one of the most important parameter in hydroforming. Basically BHF claims of responsibility for two thing and compute with those two component force. The first one is clamping force that keep dies close during process. It prevents pressure decrease and keep forming on. And the second one is net BHF that prevent wrinkling for successful workpiece. But pressure drops are hard to define where it will or when it will and that makes controlling BHF is nearly impossible with electro-hydraulic systems.

In this study an apparatus designed for providing those clamping force and net BHF mechanically. Clamping force affected by pressure and the area that pressurized liquid applied. This pressurized volume connected under blank holder and container by hydraulic transmission line for apply clamping force to keep dies close shown as Figure 5. In this way the clamping force created by pressure balance with transmitted pressurized liquid opposite side of pressurized volume that create 
clamping force first place. Downside pressured volume's sealing provided by O-rings.

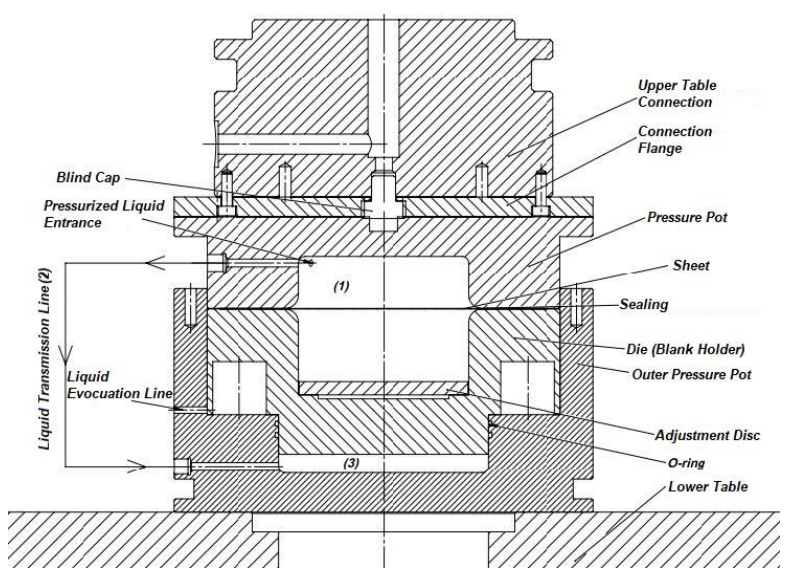

Figure 5. Apparatus for providing net BHF mechanically not affected by the pressure of liquid

Cylindrical parts were used in the experiments to find LDR and make easier to compare the results.

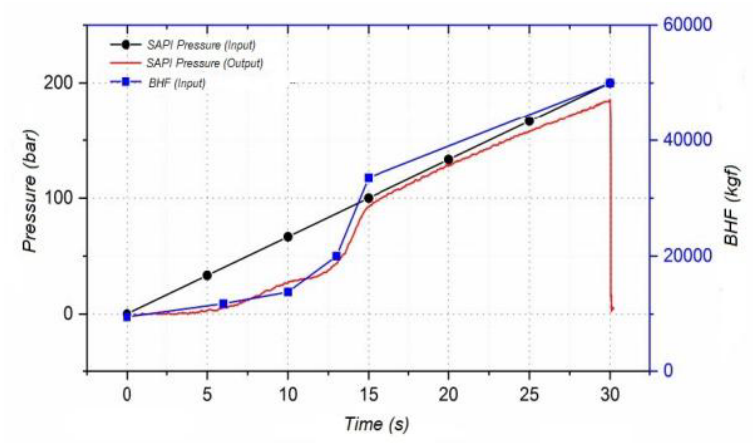

Figure 6 SAPI; BHF, Input and output of pressure

The process used for the SAPI was first loaded into the pressure curve system in a linear manner from 0 to 200 bar as seen in Figure 6 (DAPI Presure input). However, the pressure exerted by the hydroforming press may increase as much as the resistance of the sample to shape during processing. For this reason, the loading curve is formed as in the "DAPI Presure output" curve. This curve was confirmed by 3 repeated experiments and the BHF values were determined according to this curve. This change has greatly increased the success rate of the experiments.

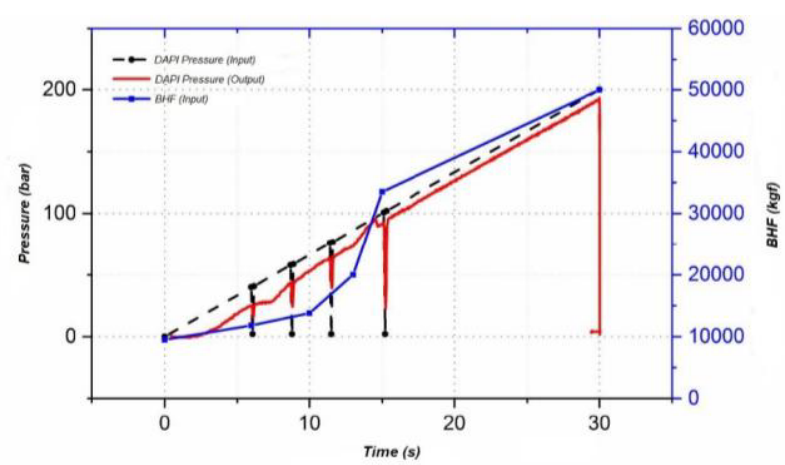

Figure 7 DAPI, 5 pressure drop; BHF, Input and output of pressure
To better understand the effect of the pressure drops count on the workpiece, it was decided to repeat the experiments, taking 10 drops instead of five pressure drops shown in Figure 7 and Figure 8. The workpieces produced using SAPI and DAPI were compared in terms of formability, thickness distribution, geometric accuracy and surface roughness.

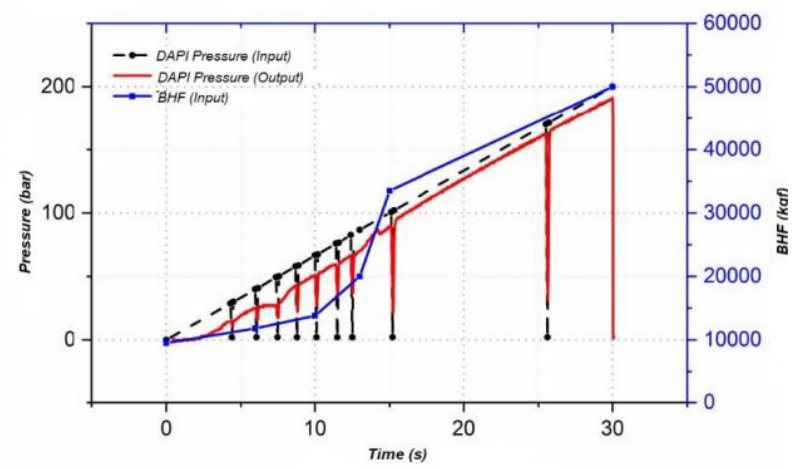

Figure 8 DAPI, 10 pressure drop; BHF, Input and output of pressure

\section{Results and discussions}

In order to determine which process is suitable for manufacturing and to decide on the usability of the DAPIs, the produced parts must be compared in terms of formability, thickness distribution and geometric accuracy.

LDR, which is indicator of the formability in sheet forming process and ratio of the primitive diameter to workpieces diameter, is used to compare formability in this study. Limiting drawing ratios were determined using optimum profiles for each process by manufacturing five workpieces. Taking these results into consideration, it has been observed that the pressure drops, which is a characteristic feature of the DAPI, is not affect formability.

It can be seen that the same sheet diameter in the processes applied and the process which causes less thinning in the sheet when using the same dies both increases the formability and the produced parts are farther away than the damage. The thickness distributions do not have superiorities to each other in all three processes. It has been determined that the maximum thinning at all processes is $18 \%$.

Optical scans were made for all three processes in order to determine their geometrical accuracy. When the processes are compared within themselves, the part profiles coincide with each other and can be produced with $0.68 \%$ dimensional error. As the number of pressure drops increases, the radius of the part improves and SAPI, DAPI 5 drops and DAPI 10 drops process radiuses were determined as $5.96,5.92$ and $5.10 \mathrm{~mm}$ respectively.

\section{Conclusion}

In this study, the usability of DAPIs were investigated in SHF-D process. An apparatus developed and 
manufactured that applying BHF synchronized with pressure by mechanically to form AA5754 material. The produced parts are compared to see the advantages and disadvantages of the processes.

The following results were obtained from experimental studies.

- The developed dies can apply the BHF depending on the pressure changes and play an active role in the success of the experiments.

- Obtained LDRs were found to be same for all processes and pressure drops are not affect formability.

-The thickness distributions gave the same results in both processes and the maximum thinning was found to be $18 \%$ in radius regions.

- The radius of the part improves and SAPI, DAPI 5 drops and DAPI 10 drops process radiuses were determined as 5.96, 5.92 and $5.10 \mathrm{~mm}$ respectively.

It has been found that press capacity can be reduced $\sim 34 \%$ in order to obtain parts having the same radius by using DAPIs.

As a result, it can be said that it is not a problem to use DAPIs in SHF-D presses, that smaller radius can be obtained and it is a great advantage in terms of cost.

\section{Acknowledgment}

This work is supported by the BAP office of Selcuk University with the project number 16201043 and Ermetal Otomotiv ve Eşya SanayiTicaret A.Ş.. Numerical verification and analysis studies are continuing in Ermetal Otomotiv ve Eşya Sanayi Ticaret A.Ş.. BAP support is profoundly acknowledged. This work has been extracted from Ahmet Can Günyadın's M.Sc. thesis.

\section{References}

1. Wang, Q., 1994, Hydromecanical deep drawing, New technol. New process. 5, 23-24

2. Şahin, S., 2004, Hidrolik şekillendirme yönteminin esasları ve sınıflandırılması, Mühendis ve Makine, Cilt:45, Sayı: 533

3. Lang L.H., Wang Z.R., Kang D.C., Yuan S.J., Zhang S.H., Danckert J., Nielsen K.B., 2004 Hydroforming highlights: Sheet hydroforming and tube hydroforming., Journal of Materials Processing Technology $151: 165-177$

4. Altan T., 2006, Process for hydroforming sheet metal, Stamping Journal, 400-418
5. Zahedi, S.A., Shamsi, A., Gorji, A., Hosseinipour, S.J., Bakhshi-Jouybari, M., 2009, Theoretical study and finite element simulation of tearing in hydroforming process, Journal of Applied Sciences, 9: 178-182.

6. Braedel M., Vavilikolane V., Bartot P., Palaniswamy H., Kaya S., Altan T., 2005,

Estimation of the optimal blank holder force and forming pressure trajectory for sheet hydroforming process with punch, ERC/NSM, Ohio State University Columbus, Ohio, Report no: ERC/NSM05-R-21

7. Zhang S.H., Danckert J., 1998, Development of hydro-mechanical deep drawing, Journal of Materials Processing Technology, 83:14-25

8. Zhang S.H., 1999, Developments in hydroforming, Journals of Materials Processing Technology, 91:226-244

9. Çelikayar, G., 2003, Yüksek basınç altında metallerin şekillendirilmesi (HIDROFORMING), III. Ulususal Hidrolik Pnömatik Kongresi ve Sergisi, 2938

10. Geren, N., Tunç, T., 2003, 3000 bar çift etkili basınç yükselticinin tasarımı ve imalatı, Çukurova Üniversitesi Mühendislik Mimarlık Fakülte Dergisi, Adana, Cilt 18 Özel sayı, 49-51

11. Geren, N., Tunç, T., 2001, Yapısal farklılıklar içeren su-jeti kesme sistemlerinin en uygununun belirlenmesi, Mühendis ve Makine Dergisi, Çukurova-Adana, Cilt 42, Sayı 500, $42-49$

12. Geren, N., Şahin, B., 1995, Su jeti ile kesme teknolojisi ve endüstriyel uygulamaları, Mühendis ve Makine Dergisi, Çukurova-Adana, Cilt 36, Sayı 424, $37-41$

13. Summers, D.A., 1995, Waterjetting tecnology, Chapman And Hall,London, ISBN0.419.19660.9

14. Singh, P.J., Benson, D., 1992, Development of phased intensifier for waterjet cutting, IngersollRand Waterjet Cutting Systems, Farmington Hills, Michigan, 306-318

15. Altan, T., 2006, "Processes for hydroforming sheet metal, Part I: Sheet hydroforming with a die", Stamping Journal-An FMA Publication, pp. 40-41.

16. Türkiye Bilimsel ve Teknik Araştırma Kurumu, 2004, Ulusal Bilin ve Teknoloji Politikalarl, 20032023 Strateji Belgesi, Versiyon 19

17. Mannesmann Rexroth, Product Catalog, RD/E/F/ 605/06.00

18. Dunkes, 2014, Product Catalog, Öttigen 